\title{
Research on Protection and Inheritance of Dawu Tapestry Belt from the Perspective of Protection of "Intangible Cultural Heritage"
}

\author{
Chunling Gao, Zhenwei Wang \\ College of Technology, Hubei Engineering University, Xiaogan Hubei, 432000, China
}

Key words: Intangible cultural heritage, Dawu tapestry belt, protection and inheritance.

\begin{abstract}
Dawu tapestry belt was included in the list of the third batch of provincial intangible cultural heritage, and is the inheritance and reflection of Chinese traditional folk crafts. This paper aims to make investigation and research on the historical background of Dawu tapestry belt based on the annals of Dawu county, then discuss the folk art characteristics and the current situation of Dawu tapestry belt, and put forward five measures for the protection and inheritance of Dawu tapestry belt on this basis.
\end{abstract}

\section{Research on Historical Background of Tapestry Belt based on Annals of Dawu County}

Dawu county is located in eastern Hubei, the western section of the Dabei Mountain. During the period of Emperors Daoguang and Xianfeng, a cloth store emerged in the southeast of Dawu, and peasants started planting cotton on a large scale, and weaved cotton cloth and sold cloth to the cloth store. According to the county annals during the period of Emperor Guangxu, "the 33*1.5 chi (=1/3meter) cotton cloth is large cloth. The cloth less than 30 chi in length and as fine and thin as satin is Chun cloth...... in Xiaogan city, the cloth shorter than 20 chi and narrower than 1 chi is cutoff cloth, which is mainly purchased by villagers. It had lasted several years that cheap grain harmed the peasants, and the weather was harsh, when almost all people made a living by this." ${ }^{[1]}$ It happened that extra longitude lines were left at both ends of a finished cloth, and weavers were loath to discard the lines, and collected the lines and weaved them into a belt for binding things. At the beginning, they weaved white belt without pattern, which was called cotton belt. Thus, Dawu tapestry belt is not silk fabrics, but is made from rough and plain cotton threads.

Later, weavers dyed belt with patterns or embroidered belt. Yet the dyed were easy to fade, and the embroidered easy to break. Hence, weavers dyed the cotton threads, and weaved the dyed threads. Before the using of chemical dyes, weavers mainly adopted indigo plant, a local plant, as the dye. According to the county annals during the period of Emperor Guangxu, "there are two kinds of bombax, purple and white. The blue can be fermented into indigo, the one looking like sophora japonica is called Guanglan, the one looking like vegetable is called Wolan, and the one looking like polygonum is called indigo plant" ${ }^{\text {"2] }}$. As stated in the Dawu county annals of 1996, "before liberation, there were dyehouses in towns and some large villages, processing materials supplied by clients. In 1949, there were 137 dyehouses in total in the county, and 154 persons engaged in the industry. A few people installed dye vat, and dyed and finished cloth by themselves.......after the victory of China in the Anti-Japanese War, dyehouses started purchasing chemical dyes and various woodwork templates with carved patterns or designs to produce black-white or colored printed cloth”[3]. It can be inferred that Dawu tapestry belts in early times were mainly in white and blue, and weaved from unicolor threads, and colored tapestry belts emerged only after the introduction of chemical dyes, namely after the victory of the Anti-Japanese War.

The delicate patterns on Dawu tapestry belt have evolved through constant improvement of weaver, and there are more than ten patterns, which were mostly developed on the basis of common items in daily life or auspicious signs, such as ginkgo, pomegranate, fish, “‡””, butterfly, cushaw squashes, honeybee, plum blossoms, orchid, bamboo, and chrysanthemum, etc. Different combinations of these patterns present us numerous different tapestry works. 
To sum up, Dawu tapestry belt had experienced the transformation from cotton belt to tapestry belt, is the result of sweat and wisdom of folk craftsman, and also a brilliant chapter of outstanding Chinese folk crafts.

\section{Folk Art Characteristics of Dawu Tapestry Belt}

Dawu tapestry belt is a belt-shaped handicraft weaved from cotton threads. In early times when Dawu tapestry belt was plain cotton belt, it was used to bind things. Later, with weavers accumulated lots of experience and became more and more skillful, they weaved belts with various delicate patterns. At that time, Dawu tapestry belt became more and more popular, and were widely used in different fields of life. The different patterns have different symbolic meanings.

For example, the one with "ginkgo" pattern was used for conveying love, "butterfly flying over cushaw squashes" expressing the will of a girl of marrying the suitor and meaning a harmonious union of a couple, “lotus, Sheng, longan, and catalpa (Lian, Sheng, Gui and Zi in pinyin)” meaning giving birth to boys, combination of pomegranate and cottonseed (Shiliu and Mianzi in pinyin) meaning having ten healthy children to fulfill the life, combination of butterfly and “ longevity, and combination of butterfly and fish standing for happiness and longevity.

During the period of the Republic of China, tapestry belt became an important integral part of local folk etiquette and custom. Unmarried girls would weave coils of tapestry belt before getting married, which would be used as dowry. At that time, advanced textile machines were imported from the west, and silk threads were widely used in Dawu. Comparing with cotton threads, silk threads are thinner, more uniform, and more lustrous. Thus, local weavers added silk threads to weave the edge of tapestry belt for beautification. Literates ladies would wave tapestry belt with characters, such as “天 长地久 (everlasting)”, “荣华富贵(high position and great wealth)”, “事事如意(Wish you all the best)”, “福如东海(happiness as immense as the Eastern Sea)”, “寿比南山(longevity)”, “双喜临门 (good things come in pairs)”. After the wedding ceremony was completed, new couple would presented tapestry belts to the present relatives and friends in token of gratitude. If any one died, tapestry belt would be used as rein of paper horse or for binding sedan made of paper, or hanging evocation banners. Therefore, tapestry belt prevailed in the period of the Republic of China.

The craftsmanship of tapestry belt is of distinctive folk characteristics. "Back-rest chair, long bench, and log ladder all can be used as machine tool, and chopsticks and bands can be used for weaving jacquard longitudinal lines.” ${ }^{[4]}$ No shuttle and reed were needed, but the weft was fed in the cloth-fell by hand, and knife-shaped bamboo or wood chip was used for lightly chopping. It can be seen that the process of tapestry belt weaving is a completely manual process. The key factors of tapestry belt production are thread pulling and pattern. The number of longitude lines depends on the width and pattern of belt. Ms. Chen Dengmei, one of the inheritor of tapestry belt, introduced in an interview the key points of tapestry belt weaving: "For thread pulling, the chair should be firmly placed, even force is required, the colored threads should be clearly remembered, longitudinal lines should not be confused, the knife should be held levelly, longitudinal lines should be uniformly pulled, and take-up should be made accurately.", which almost summarized the techniques and experiences of tapestry belt weaving accumulated by the ancestors.

\section{Analysis of Current Situation of Dawu Tapestry Belt}

Presently, the main problem of Dawu tapestry belt is the shortage of inheritor. Although local support gives strong support, the current situation of Dawu tapestry belt is still not optimistic for the following reasons.

Firstly, the government just can give limited support, and there are few inheritors. Hubei Provincial Department of Culture has organized two sessions of intangible cultural heritage representative inheritor training class. The class covers multiple intangible cultural heritage items, only one trainee is accepted for each item, the training time is as short as two or three days, and 
trainees enjoy no pick-up or see-off service. Though the government required the subordinate units to stress the training program again and again, it is beyond all doubt that the government just can give limited support.

Secondly, ordinary people have little knowledge of Dawu tapestry belt. Although Dawu tapestry belt has been included in the list of intangible cultural heritage, few researches on Dawu tapestry belt have been made, and the few articles on Dawu tapestry belt are much of a muchness. Hence, further research, investigation and analysis are needed, which is a time-consuming arduous task.

Thirdly, the present market value of Dawu tapestry belt doesn't reflect its real value. The main reason for that there are few inheritors is low profit from weaving Dawu tapestry belt. Thus, most young people would like to go out to work rather than stay at home and develop Dawu tapestry belt. Dawu county is economically backward, which was caused by historical reasons. The government and related department are striving to find opportunity for revitalizing the market value of Dawu tapestry belt which is of commercial use inherently.

According to the current situation, the researches on the protection and inheritance of Dawu tapestry belt as one of the "intangible cultural heritages" appear to be of great significance.

\section{Exploration of Protection and Inheritance of Dawu Tapestry Belt}

The following is about the issues on protection and inheritance of Dawu tapestry belt from five aspect. From the perspective of protection of "intangible cultural heritage", the five aspects will provide or enlighten us with measures for protection and inheritance of Dawu tapestry belt.

\section{Productive Protection of "Intangible Cultural Heritage"}

Since generally "intangible cultural heritages" are of distinctive regional characteristics and folk characteristics, there exist contradictions between protection and development of "intangible cultural heritages", between profit and reality remaining, and between modern machine production and traditional handicraft, etc. Dawu tapestry belt falls into traditional handicraft, which is featured by productivity since its emergence. Therefore, it is proper to protect Dawu tapestry belt by means of productive protection.

The protection method of the government mainly refers to synchronizing government management and market operation. "Since the heritage of the minorities are in imminent danger, industrialization development is one of the effective ways to realize sustainable development, namely transforming intangible cultural heritage resources into cultural competitiveness of cultural industry development, giving them the capability of self-development, and forming a virtuous cycle through protection and development." ${ }^{[5]}$ Hence, it would be a good method to make Dawu tapestry belt adapt to the market requirements via productive protection. But productive protection is likely to step into the wrong road of seeking market and economic benefits as an end in itself, damaging the original ecology of Dawu tapestry belt, and reducing it into a ready source of money. This cannot make for the protection and inheritance of Dawu tapestry belt, and will damage the original ecology of Dawu tapestry belt, which is worth noting.

\section{Creative Protection of "Intangible Cultural Heritage”}

The concept of cultural creativity gradually became prevailing since the $1990 \mathrm{~s}$. In the $21^{\text {st }}$ century, cultural creative industry parks grow vigorously in big cities in China. As the entrepreneurial platform of the young generation, cultural creative industry park is a usable resource. I hold that cultural creativity industry is one of the important ways to integrate intangible cultural heritages into social and public life.

Treating "intangible cultural heritage" as a valuable resource, and developing Dawu tapestry belt by means of cultural creativity industry are a unique method subordinate to productive production, which can bring inexhaustible resources with Chinese characteristics to the cultural creativity industry, and also preserve Dawu tapestry belt handicraft, and make it popular to people. 
There are three modes of creative protection of "intangible cultural heritage", namely "improvement, creation and integration. Improvement refers to upgrading and improving the products and services of "intangible cultural heritage" based on its cultural kernel and essence to adapt to the consumption psychology and demands, and aesthetic trend of modern people......Creation refers to combining "intangible cultural heritage" with modern technology, and giving full play to creativity, to produce cultural products of new form...... Integration refers to integrating "intangible cultural heritage" elements into other industries and products by means of design, etc." ${ }^{[6]}$ The foregoing three modes basically have summarized creative protection, and are worth learning and researching. The main channel is to make improvement, creation or integration via the platform of cultural creativity industry, to realize the inheritance and development of “intangible cultural heritage” by itself.

\section{Scientific Protection of "Intangible Cultural Heritage”}

Scientific protection of "intangible cultural heritage" refers to inheritance and protection on the premise of historical and geological research and investigation of "intangible cultural heritage" and in consistency with the inherent laws of the intangible cultural heritage, namely its inheritance way in the history, and whether individuals or groups can access to the market, etc.; and protection from the perspective of inheritor (craftsman) in compliance with the "people-oriented" tenet.

Besides, because of the problems arising from overdevelopment of tourism, the government must realize that it should not seek economic benefits only, and ignore that the authenticity is also one of the connotations of scientific protection of "intangible cultural heritage".

\section{Archive-based Protection of "Intangible Cultural Heritage”}

"Intangible cultural heritage" archives are the firsthand information for learning about Dawu tapestry belt, and play a fundamental role in its protection and inheritance. The "intangible cultural heritage" archive-based measures such as general survey, filing, database construction, and archives preservation are a static protection way. To realize this way, the internet will be resorted to, the "intangible cultural heritage" archives are required to be timely updated, and "intangible cultural heritage" archiving should be included in normal daily work. Presently, archive-based protection is still not sound, the archive contents are not complete, there are few image and audio materials, and the materials are updated slowly, not clearly classified and inefficiently utilized. Thus, the functions of network technology have not been completely tapped. This can be improved manually, to record the protection of "intangible cultural heritage".

\section{Art Education-based Protection of "Intangible Cultural Heritage"}

It was proposed to treat "intangible cultural heritage" as a valuable resource as above, and this resource can be effectively utilized to art education. Generally, the folk art forms and expression ideas coincide with the course contents of art education. Popularizing Dawu tapestry belt via classroom teaching to students can draw the handicraft close to people's life, and help students get a better knowledge of Chinese folk traditional cultures.

Undoubtedly, “intangible cultural heritage” can be taken as material and resource for art education, and the whole procedure of folk craftsman also conforms to the well-established teaching system of modern art education and the requirements of the state for trait-oriented education, and makes for realization of the hope of Mr. Cai Yuanpei for "revitalizing the country through aesthetic education”.

The five points above are superficial views on the protection and inheritance of Dawu tapestry belt from the perspective of "intangible cultural heritage". Dawu tapestry belt is indispensable for Chinese folk traditional culture, witnessed the wisdom and craftsmanship of Chinese people, embodies the yearn of laboring people in ancient China for a good life, and is a valuable resource and heritage of the world. 


\section{Acknowledgments}

This paper is a humanistic and social science guidance project of Hubei Provincial Department of Culture, numebred 16G283.

\section{References}

[1] Qing. Zhu Ximen et al. (revise), Shen Yongzeng (write): Hubei Province Xiaoguan County Annals (Five Volumes) the Eighth Year of the Period of Emperor Guangxu (photocopy), Taipei: printed and distributed by Cheng Wen Publishing Co., Ltd., 64th year of the Republic of China, p451.

[2] Qing. Zhu Ximen et al. (revise), Shen Yongzeng (write): Hubei Province Xiaoguan County Annals (Five Volumes) the Eighth Year of the Period of Emperor Guangxu (photocopy), Taipei: printed and distributed by Cheng Wen Publishing Co., Ltd., 64th year of the Republic of China, p443.

[3] Hubei Province Dawu County Compilation Committee of Local Chronicles: Annals of Dawu County, Wuhan: Hubei Publishers of Science and Technology, Oct. 1996, p209.

[4] Editorial Liu Bo: Chinese Folk Art Dictionary, Beijing: Culture and Art Publishing House, Jun. 2006, p586.

[5] Ding Zhicai: Productive Protection of Intangible Cultural Heritage of Minorities from the perspective of Folk Culture Industry-Broche Craftsmanship of the Zhuang Ethnic Group, Social Sciences in Yunnan, 2013(5), p101.

[6] Li Zhixiong: Creative Protection: New Protection Mode of "Intangible Cultural Heritage"in the Era of Cultural Creativity Industry, Guangxi Social Sciences, 2013(10), p49. 